\title{
Elevated expression of cyclooxygenase- 2 and microsomal prostaglandin E synthase-1 in primary sclerosing cholangitis: Implications for cholangiocarcinogenesis
}

\author{
YASUTAKA ISHII, TAMITO SASAKI, MASAHIRO SERIKAWA, TOMOYUKI MINAMI, AKIHITO OKAZAKI, \\ MASANOBU YUKUTAKE, TAKASHI ISHIGAKI, KEIICHI KOSAKA, TERUO MOURI, SATOSHI YOSHIMI, \\ AKINORI SHIMIZU, TOMOFUMI TSUBOI and KAZUAKI CHAYAMA \\ Department of Gastroenterology and Metabolism, Applied Life Sciences, \\ Institute of Biomedical and Health Sciences, Hiroshima University, \\ 1-2-3 Kasumi, Minami-ku, Hiroshima 734-8551, Japan
}

Received May 28, 2013; Accepted June 5, 2013

DOI: 10.3892/ijo.2013.2038

\begin{abstract}
Cholangiocarcinoma (CCA) occurs frequently in primary sclerosing cholangitis (PSC). Cyclooxygenase-2 (COX-2) and microsomal prostaglandin E synthase-1 (mPGES-1) induced by inflammation are believed to mediate prostaglandin $\mathrm{E}_{2}\left(\mathrm{PGE}_{2}\right)$ production thereby promoting carcinogenesis. Their expression in PSC-associated CCA tissues and non-neoplastic bile duct epithelial cells (BDECs) in PSC was investigated. COX-2 and mPGES-1 levels in 15 PSC patients (7 with CCA) were scored using immunohistochemical staining. The results were compared with those obtained in CCA tissues and non-neoplastic BDECs (controls) of 15 sporadic CCA patients. Non-neoplastic BDECs from large and small bile ducts were investigated separately. The mRNA expression levels of COX-2 and mPGES-1 in CCA tissues were analyzed by quantitative polymerase chain reaction. Ki-67 immunostaining was performed to evaluate cell proliferation. COX-2 was strongly expressed in PSC-associated CCA tissues and nonneoplastic BDECs in PSC. This expression was significantly upregulated in both compared with sporadic CCA tissues and non-neoplastic BDECs in sporadic CCA (both $\mathrm{P}<0.01$ ). mPGES-1 was expressed at moderate to strong levels in PSC. Compared with controls, the expression was significantly higher in non-neoplastic small BDECs $(\mathrm{P}<0.01)$. COX-2 mRNA levels were significantly higher in PSC-associated tissues than in sporadic CCA tissues $(\mathrm{P}<0.01)$. Conversely, no differences were observed in mPGES-1 mRNA levels.
\end{abstract}

Correspondence to: Dr Yasutaka Ishii, Department of Gastroenterology and Metabolism, Applied Life Sciences, Institute of Biomedical and Health Sciences, Hiroshima University, 1-2-3 Kasumi, Minami-ku, Hiroshima 734-8551, Japan

E-mail: d103876@hiroshima-u.ac.jp

Key words: primary sclerosing cholangitis, cyclooxygenase-2, microsomal prostaglandin E synthase-1, cholangiocarcinoma
Ki-67 labeling indices were higher in PSC-associated CCA tissues and non-neoplastic BDECs in PSC than in controls. In conclusion, COX-2 and mPGES-1 were highly expressed in PSC-associated CCA tissues and non-neoplastic BDECs in PSC, suggesting the involvement of COX-2 and mPGES-1 in cholangiocarcinogenesis.

\section{Introduction}

Primary sclerosing cholangitis (PSC), a chronic inflammatory disease, is characterized by fibrous thickening of the bile duct walls and causes multiple stenoses of the intra- and extra-hepatic bile ducts. Cholangiocarcinoma (CCA) occurs with high frequency (5-13\%) in PSC (1-4). CCA is a prognostic factor for PSC. However, the underlying mechanism of carcinogenesis is not well understood.

There are many gastrointestinal cancers that develop because of underlying chronic inflammation such as that found in PSC. These include gastric cancers caused by chronic gastritis due to Helicobacter pylori infection, hepatocellular carcinoma caused by chronic hepatitis due to hepatitis B virus or hepatitis C virus infection, colorectal cancer due to inflammatory bowel disease, and esophageal adenocarcinoma due to Barrett's esophagus. The expression of cyclooxygenase-2 (COX-2) and microsomal prostaglandin $\mathrm{E}$ synthase-1 (mPGES-1) is induced by inflammation, and studies suggest that these enzymes are involved in the development of these carcinomas (5-11). COX-2 and mPGES-1 are both involved in the arachidonate cascade: COX-2 converts arachidonic acid to prostaglandin $\mathrm{H}_{2}\left(\mathrm{PGH}_{2}\right)$ and mPGES-1 converts $\mathrm{PGH}_{2}$ to $\mathrm{PGE}_{2}$. Thus, $\mathrm{PGE}_{2}$ is elevated because of increased COX-2 and mPGES-1 expression, and it plays an important role in carcinogenesis by promoting cell proliferation, angiogenesis, cell infiltration and inhibiting apoptosis (12). CCA arising in association with PSC (PSC-associated CCA) also develops because of underlying chronic inflammation, which implies the involvement of COX-2 and mPGES-1 in cholangiocarcinogenesis. However, the mechanism has not yet been investigated. 
To elucidate the carcinogenic mechanisms associated with PSC, this study investigated COX-2 and mPGES-1 expression in PSC-associated CCA tissues, CCA unrelated to PSC (sporadic CCA) tissues, non-neoplastic bile duct epithelial cells (BDECs) in PSC, and non-neoplastic BDECs in sporadic CCA.

\section{Materials and methods}

Tissue samples. All tissue samples in this study were obtained from Hiroshima University Hospital patients by surgical resection or biopsy. PSC tissue samples were obtained from 15 patients. Seven of these patients had PSC-associated CCA, of whom 2 had intrahepatic CCA and 5 had extrahepatic CCA. The histological type was well-differentiated tubular adenocarcinoma for all patients. The control group was comprised of 15 sporadic CCA patients, of whom 7 had intrahepatic CCA and 8 had extrahepatic CCA (6 had perihilar extrahepatic bile duct tumors and two had distal extrahepatic bile duct tumors). Histologically, they were well-differentiated tubular adenocarcinomas (6 patients), moderately differentiated tubular adenocarcinomas (6 patients), and poorly differentiated tubular adenocarcinoma (3 patients).

Sections fixed in $10 \%$ buffered formalin for $24 \mathrm{~h}$ were used for immunohistochemical staining. CCA tissues were frozen rapidly in liquid nitrogen and stored at $-80^{\circ} \mathrm{C}$ before being used for reverse transcription-polymerase chain reaction (RT-PCR). This study was approved by the Hiroshima University Hospital ethics committee.

Immunohistochemistry and evaluation. The streptavidin-biotin method was used for immunohistochemical staining of COX-2 and mPGES-1. Four-micron thick paraffin-embedded sections were first deparaffinized and soaked for $30 \mathrm{~min}$ in $3 \%$ hydrogen peroxide solution to inhibit endogenous peroxidase activity. They were then soaked in Epitope Retrieval Solution, pH 9.0, at $95^{\circ} \mathrm{C}$ in a hot water bath for $40 \mathrm{~min}$ (Novocastra Laboratories Ltd., Newcastle upon Tyne, UK). After being washed in phosphate-buffered saline (PBS) (pH 7.4), the sections were reacted in $10 \%$ normal goat serum at room temperature for $10 \mathrm{~min}$ in order to block non-specific antibody responses. The sections were then incubated with primary antibodies overnight at $4^{\circ} \mathrm{C}$. The primary antibodies were as follows: polyclonal rabbit anti-COX-2 antibodies (Immuno-Biological Laboratories Co. Ltd, Gunma, Japan) at a dilution of 1:200 and polyclonal rabbit anti-mPGES-1 antibodies (Cayman Chemical, Ann Arbor, MI, USA) at a dilution of 1:500. For the control, normal rabbit IgG (Santa Cruz Biotechnology, Dallas, TX, USA) was used instead of the primary antibodies. After washing in PBS, the sections were incubated with biotin-labeled secondary antibodies at room temperature for $30 \mathrm{~min}$. The sections were then washed in PBS and incubated with peroxidase-labeled streptavidin at room temperature for $30 \mathrm{~min}$. They were visualized using a 3 3'-diaminobenzidine tetrahydrochloride substrate (Dako Japan, Kyoto, Japan) and counterstained using Mayer's hematoxylin.

Ki-67 immunostaining was performed using Ventana BenchMark Ultra (Ventana Medical Systems, Tucson, AZ, USA) automatic staining device and rabbit anti-Ki-67 antibodies (Ki-67) as the primary antibody.

COX-2 and mPGES-1 expression in CCA tissues and non-neoplastic BDECs was evaluated using a method reported previously (13). The staining intensity for each section was scored 0-3 as follows: 0 , negative staining; 1 , weakly positive staining; 2 , moderately positive staining; and 3 , strongly positive staining. The maximum intensity of staining and the most extensive intensity level of positive cells were evaluated separately. The 'extent of distribution' of positive cells for each section was scored $0-3$ as follows: 0 , negative; $1,1-33 \% ; 2,34-66 \%$; and $3,67-100 \%$. The total score of these three parameters was then used to evaluate each section. The median score for each histological category was used to perform a statistical comparison of COX-2 and mPGES-1 immunoreactivity.

$\mathrm{Ki}-67$ was used to calculate the proportion of positive cells in CCA tissues and non-neoplastic BDECs. In total, 500 cells were counted in areas with many positive cells, and the percentage of positive cells relative to the total cell count was expressed as the $\mathrm{Ki}-67$ labeling index (LI).

For non-neoplastic BDECs, large BDECs, comprising those from the extrahepatic bile duct to the second branches of the left and right hepatic ducts, and small BDECs, comprising those from septal and interlobular bile ducts, were evaluated separately. The non-neoplastic BDECs of sporadic CCA patients were used as controls for comparison with those from PSC patients.

Immunostaining of cancer tissue was possible for all patients. Immunostaining of non-neoplastic large BDECs was possible for 11 PSC and 14 control patients. Immunostaining of non-neoplastic small BDECs was possible for 9 PSC and 14 control patients.

$R T-P C R$. Total RNA was extracted and purified from frozen tumor sections using the RNeasy mini kit (Qiagen, Germantown, MA, USA). RT-PCR was performed in two steps. First, total RNA was converted to cDNA using the PrimeScript RT-PCR Kit (Takara Bio Inc., Shiga, Japan). A $20 \mu 1$ reaction mixture containing $200 \mathrm{ng}$ total RNA was prepared and subjected to reverse transcription at $42^{\circ} \mathrm{C}$ for $30 \mathrm{~min}$. The mixture was then incubated at $95^{\circ} \mathrm{C}$ for $5 \mathrm{~min}$ to deactivate reverse transcriptase and then cooled to $4^{\circ} \mathrm{C}$.

The Applied Biosystems 7900HT Fast Real-time PCR System (Applied Biosystems, Foster City, CA, USA) was used to perform RT-PCR. Each PCR reaction mixture contained $1 \mu \mathrm{l}$ cDNA template, $10 \mu 1$ Power SYBR-Green PCR Master mix (Applied Biosystems), 8 pmol primer set, and water to make a total volume of $20 \mu 1$. First denaturation was performed at $95^{\circ} \mathrm{C}$ for $10 \mathrm{~min}$ and then 50 -cycle PCR $\left(95^{\circ} \mathrm{C}\right.$ for $10 \mathrm{~min}, 50^{\circ} \mathrm{C}$ for $1 \mathrm{~min}$ ) was conducted. Primer sequences were as follows: COX-2 sense, 5'-TTCAAATGAGATTGTGGAAAATTGCT-3'; antisense, 5'-GATCATCTCTGCCTGAGTATCTT-3'; mPGES-1 sense, 5'-ACCAGACCATGGGCCAAGAG-3'; antisense 5'-GGC CCACCACAATCTGGAA-3'. Amplification results were analyzed using sequence detection system 2.4.1 software (Applied Biosystems). mRNA expression levels were corrected using glyceraldehyde 3-phosphate dehydrogenase as a housekeeping gene and expressed as arbitrary units.

Statistical analysis. Statistical analysis was performed using JMP 9.0.0 (SAS, Cary, NC, USA). All results are expressed as means \pm SEM. Continuous variables between the two groups were compared using the Mann-Whitney $\mathrm{U}$ test. $\mathrm{P}<0.05$ was considered statistically significant. 


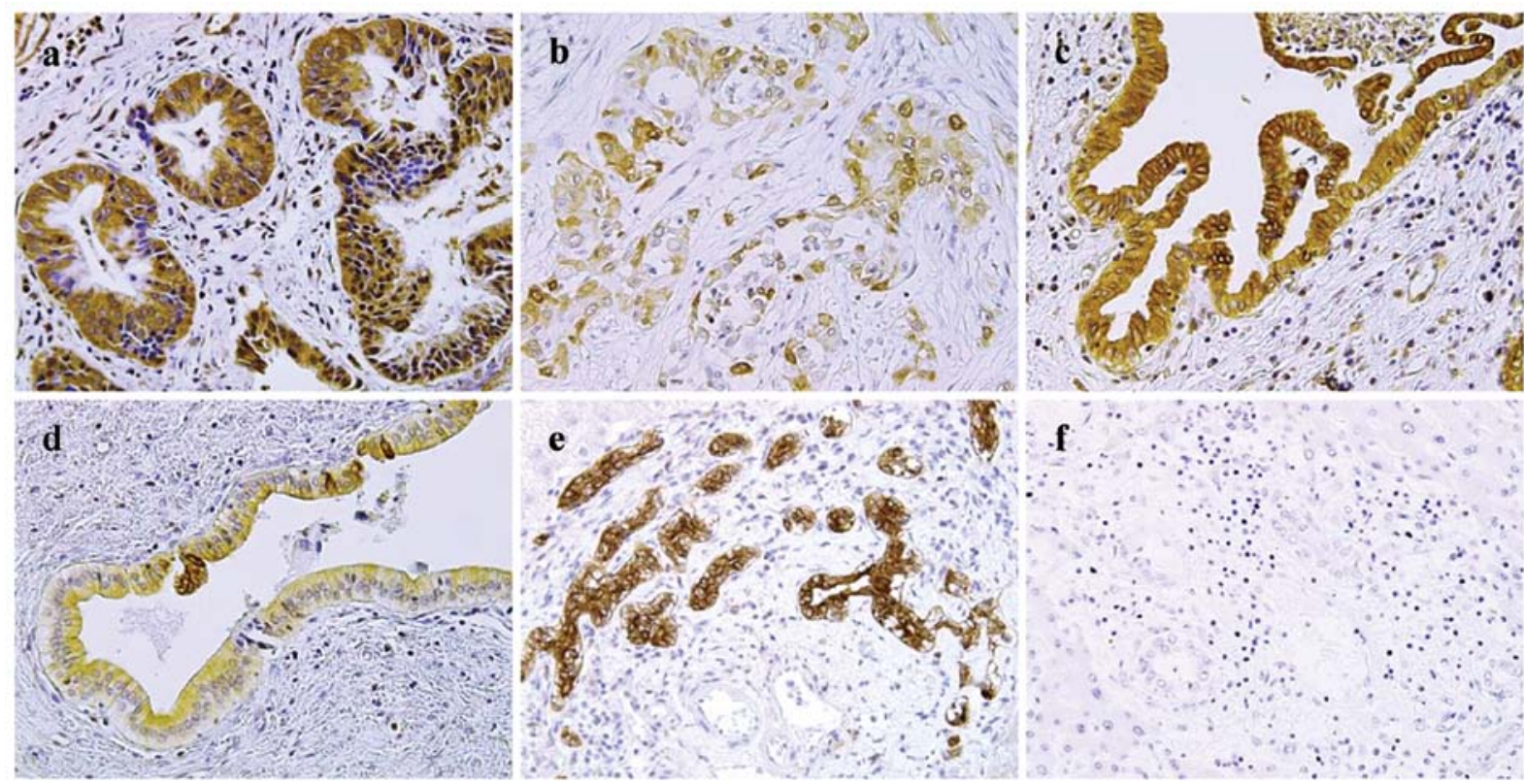

Figure 1. Immunohistochemical staining of COX-2 in CCA cells and non-neoplastic bile duct epithelial cells. Results are as follows: (a) strongly positive in PSC-associated CCA; (b) weakly positive in sporadic CCA; (c) strongly positive in large bile duct epithelial cells in PSC; (d) weakly positive in large bile duct epithelial cells in controls; (e) strongly positive in small bile duct epithelial cells in PSC; (f) negative staining in small bile duct epithelial cells in controls. Original magnification, $\mathrm{x} 200$.

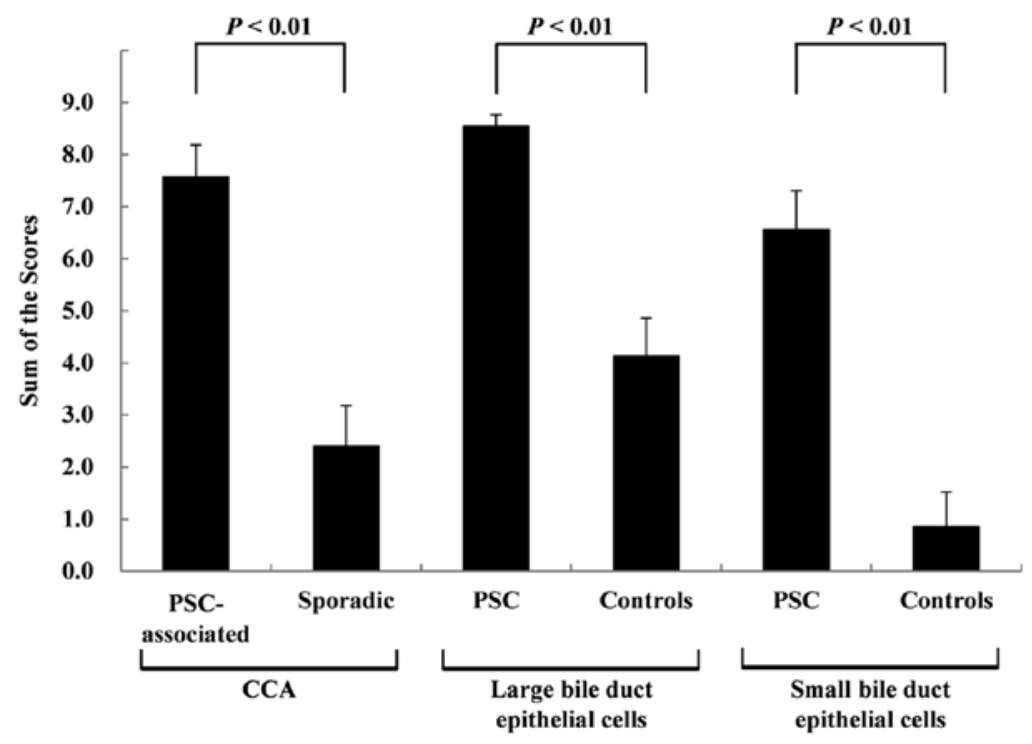

Figure 2. Scores representing immunoreactivity of COX-2 in CCA tissues and non-neoplastic bile duct epithelial cells. Data are expressed as means \pm SEM

\section{Results}

Immunohistochemical analysis of COX-2. Examples of COX-2 staining are shown in Fig. 1. In PSC-associated CCA tissues (Fig. 1a), COX-2 expression was strong in all of the patients. In the sporadic CCA tissues (Fig. 1b), COX-2 expression was observed for $7 / 15$ patients (47\%). In the non-neoplastic large BDECs, COX-2 expression was strong for all PSC patients (Fig. 1c), whereas the expression was observed in 12 of 15 control patients (80\%; Fig. 1d), and immunoreactivity was lower than that in the PSC patients. In the non-neoplastic small BDECs, COX-2 expression was moderate to strong for all PSC patients (Fig. 1e), whereas the expression was negative for 12 of 14 control patients (86\%; Fig. 1f). COX-2 expression scores for the CCA tissues and non-neoplastic BDECs are shown in Fig. 2. The scores for the PSC-associated CCA tissues were significantly higher $(\mathrm{P}<0.01)$ than those for the sporadic CCA tissues at $7.57 \pm 0.61$ and $2.40 \pm 0.78$, respectively. The scores for the non-neoplastic large BDECs in the PSC patients were significantly higher $(\mathrm{P}<0.01)$ than those in the control patients at $8.55 \pm 0.22$ and $4.13 \pm 0.73$, respectively. The scores for the non-neoplastic small BDECs in the PSC patients were significantly higher $(\mathrm{P}<0.01)$ than those for the control patients at $6.56 \pm 0.75$ and $0.86 \pm 0.66$, respectively. No 


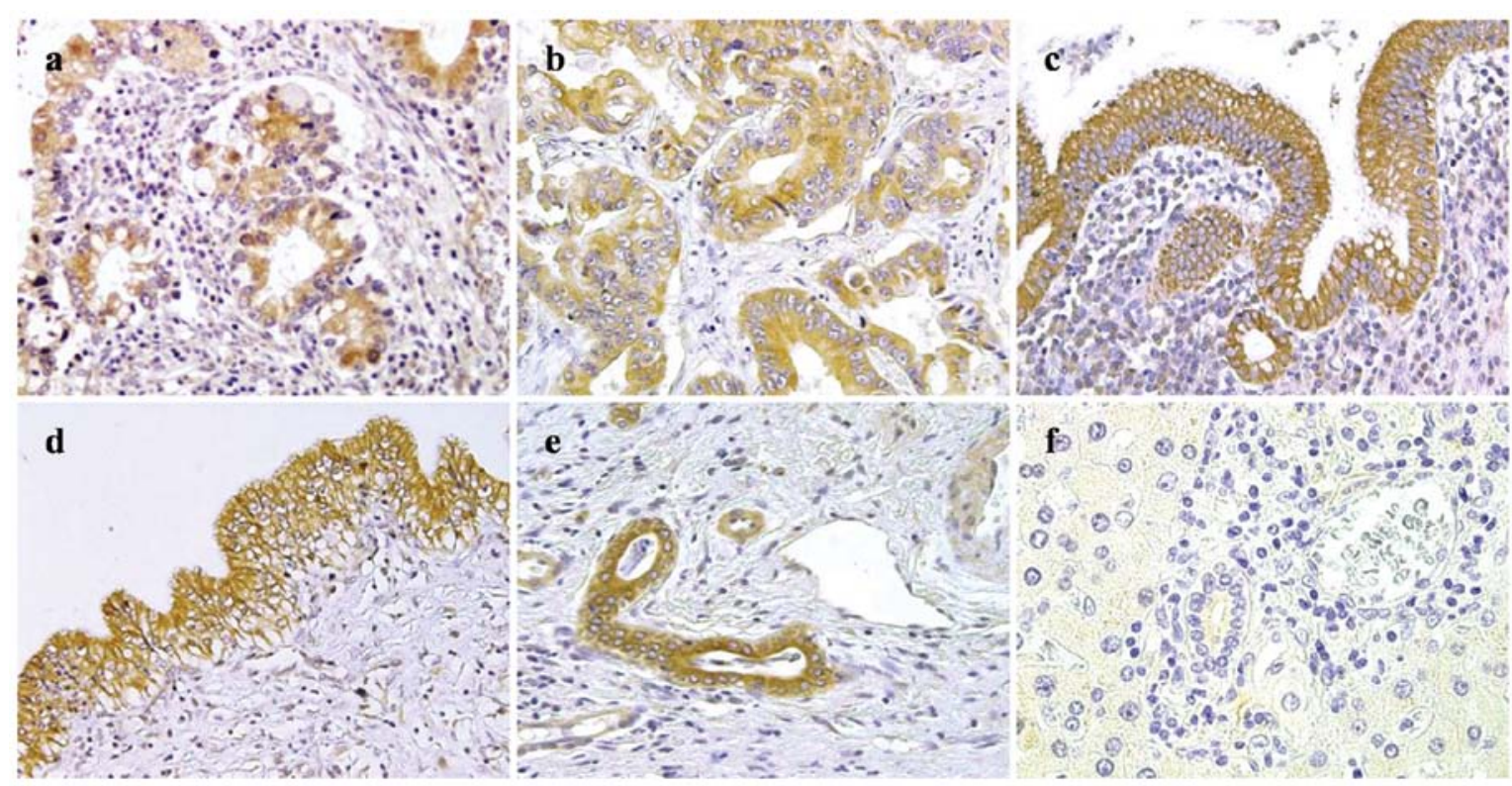

Figure 3. Immunohistochemical staining of mPGES-1 in CCA tissues and non-neoplastic bile duct epithelial cells. Results are as follows: (a) moderately positive in PSC-associated CCA tissues; (b) moderately positive in sporadic CCA tissues; (c) strongly positive in large bile duct epithelial cells of PSC; (d) moderately positive in large bile duct epithelial cells of controls; (e) strongly positive in small bile duct epithelial cells of PSC; (f) negative staining in small bile duct epithelial cells of controls. Original magnification, $\mathrm{x} 200$.

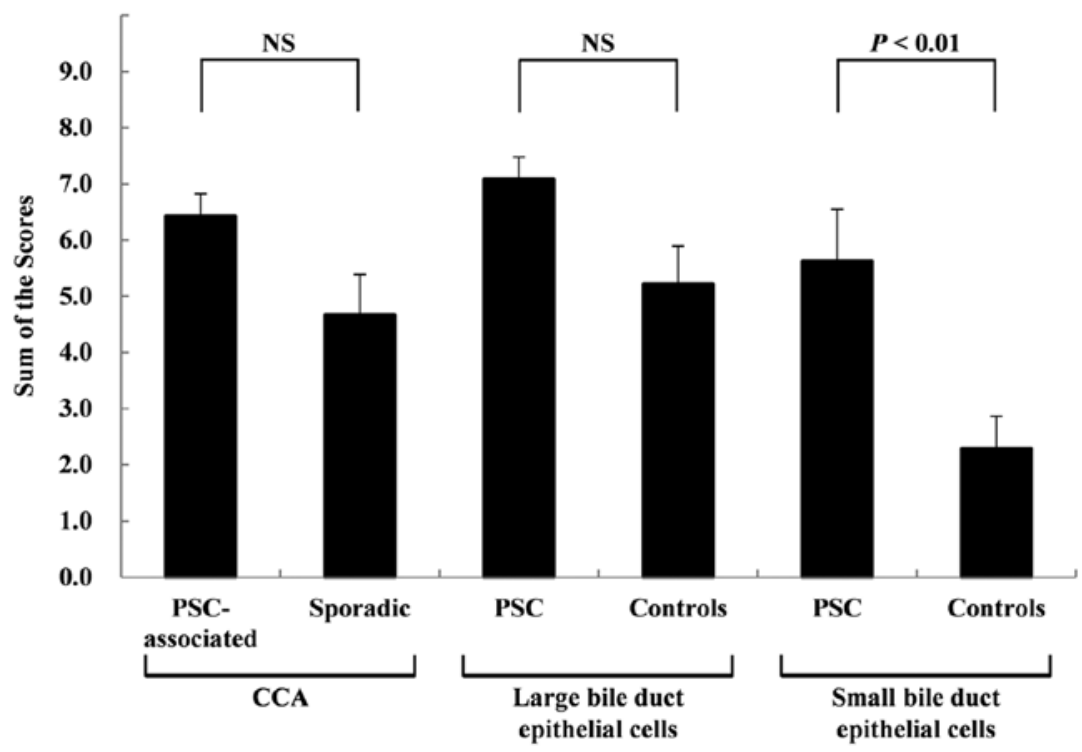

Figure 4. Scores representing immunoreactivity of mPGES-1 in CCA tissues and non-neoplastic bile duct epithelial cells. Data are expressed as means \pm SEM. NS, not significant.

significant differences were observed between the scores for the non-neoplastic BDECs in the PSC patients with CCA and PSC patients without CCA (data not shown).

Immunohistochemical analysis of mPGES-1. Examples of mPGES-1 staining are shown in Fig. 3. mPGES-1 expression in the PSC-associated CCA tissues (Fig. 3a) was moderate to strong for the majority of patients. Expression was observed in sporadic CCA tissues (Fig. 3b) in the majority of patients, but immunoreactivity in the sporadic CCA tissues was lower than that in the PSC-associated CCA tissues. mPGES-1 expression was moderate to strong in the non-neoplastic large BDECs of the majority of PSC tissues (Fig. 3c) and control (Fig. 3d) patients. Moderate or higher expression was observed in the non-neoplastic small BDECs of 8 of 9 PSC patients (89\%; Fig. 3e), whereas the expression was negative in the non-neoplastic small BDECs of 6 of 13 control patients (43\%; Fig. 3f). The scores for mPGES-1 expression are shown in Fig. 4. No significant differences were observed between the scores for the PSC-associated and sporadic CCA tissues at $6.43 \pm 0.40$ and $4.67 \pm 0.72$, respectively. No significant differences were observed between the scores for the 


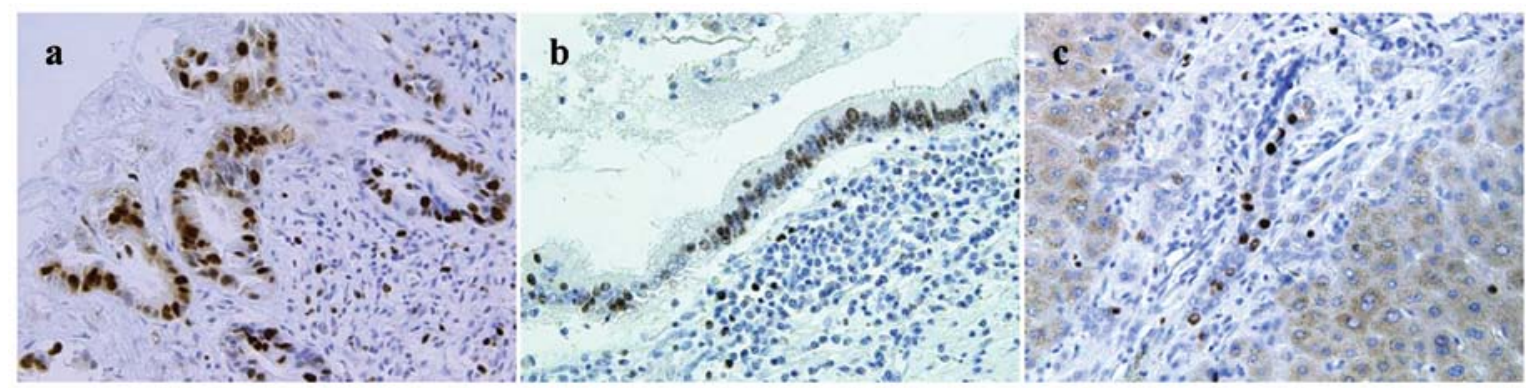

Figure 5. Immunohistochemical staining of Ki-67 in PSC. Results are as follows: (a) PSC-associated CCA tissues; (b) non-neoplastic large bile duct epithelial cells; (c) non-neoplastic small bile duct epithelial cells. Original magnification, x200.

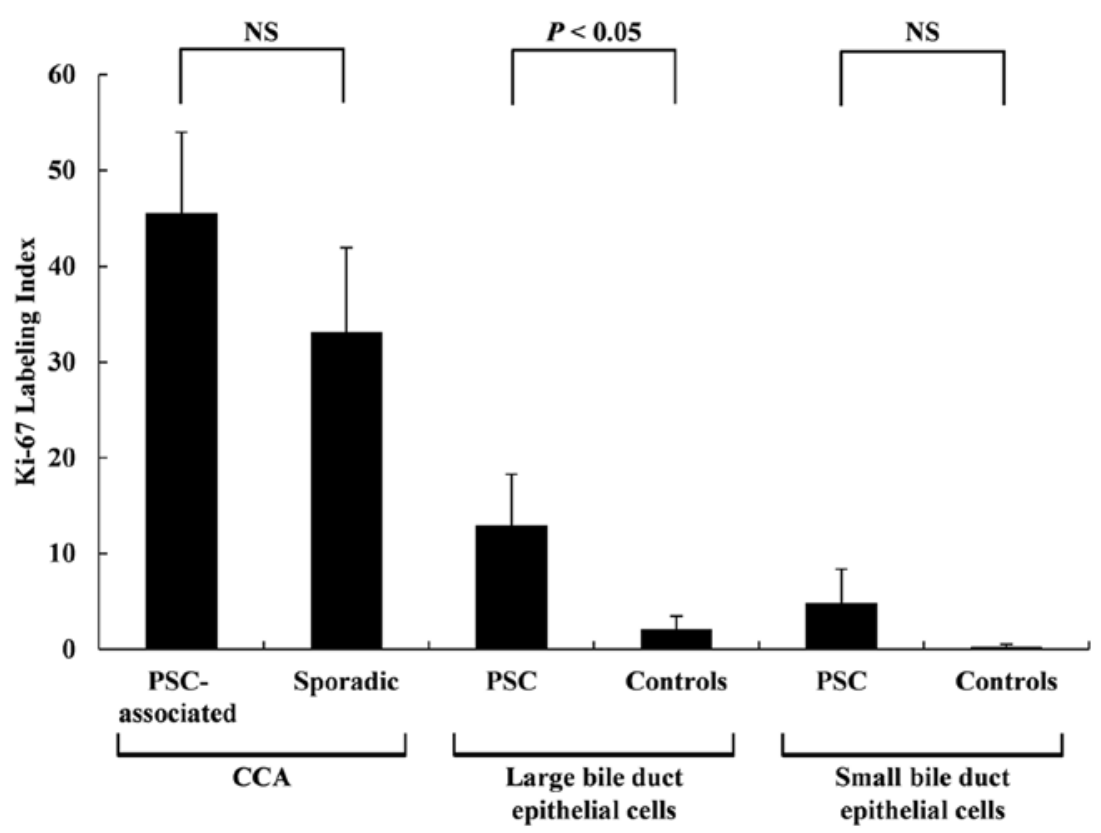

Figure 6. Ki-67 labeling index in CCA tissues and non-neoplastic bile duct epithelial cells. Data are expressed as means \pm SEM. NS, not significant.

non-neoplastic large BDECs in the PSC and control patients $(7.09 \pm 0.39$ and $5.21 \pm 0.68$, respectively). However, a trend of stronger expression was observed in the non-neoplastic large BDECs of the PSC patients. The scores for the non-neoplastic small BDECs in the PSC patients were significantly higher $(\mathrm{P}<0.01)$ than those in the control patients at 5.63 \pm 0.92 and $2.29 \pm 0.58$, respectively.

Ki-67 labeling index. Examples of Ki-67 staining are shown in Fig. 5. The Ki-67 LI results are shown in Fig. 6. No statistically significant differences were observed between the Ki-67 LI for the PSC-associated CCA tissues and the sporadic CCA tissues at 45.6 \pm 8.4 and 33.1 \pm 8.8 , respectively, although a trend of higher Ki-67 LI was observed for the PSC-associated CCA tissues. The Ki-67 LI for the non-neoplastic large BDECs in the PSC patients were significantly higher $(\mathrm{P}<0.01)$ than those in the control patients at $13.0 \pm 5.3$ and $2.1 \pm 1.4$, respectively. No statistically significant differences were observed between Ki-67 LI for the non-neoplastic small BDECs of the PSC and control patients $(4.9 \pm 3.5$ and $0.28 \pm 0.28$, respectively), but a trend of higher Ki-67 LI was observed in the non-neoplastic small BDECs of the PSC.

RT-PCR. COX-2 and mPGES-1 mRNA levels in the CCA tissues were evaluated using quantitative real-time PCR. This was performed using the tissues samples of 7 PSC-associated CCA patients and 15 sporadic CCA patients. The COX-2 mRNA levels were significantly higher $(\mathrm{P}<0.05)$ in the PSC-associated CCA tissues than in the sporadic CCA tissues. In contrast, no significant differences in mPGES-1 mRNA expression were observed between the two groups (Fig. 7).

\section{Discussion}

This study indicated that COX-2 and mPGES-1 expression was upregulated in both CCA tissues and non-neoplastic BDECs in PSC patients. COX-2 expression is known to be upregulated in inflammatory diseases that give rise to cancer (5-11) as well as in various carcinomas (14-17) and is believed to be involved in carcinogenesis and tumor proliferation. High COX-2 expres- 

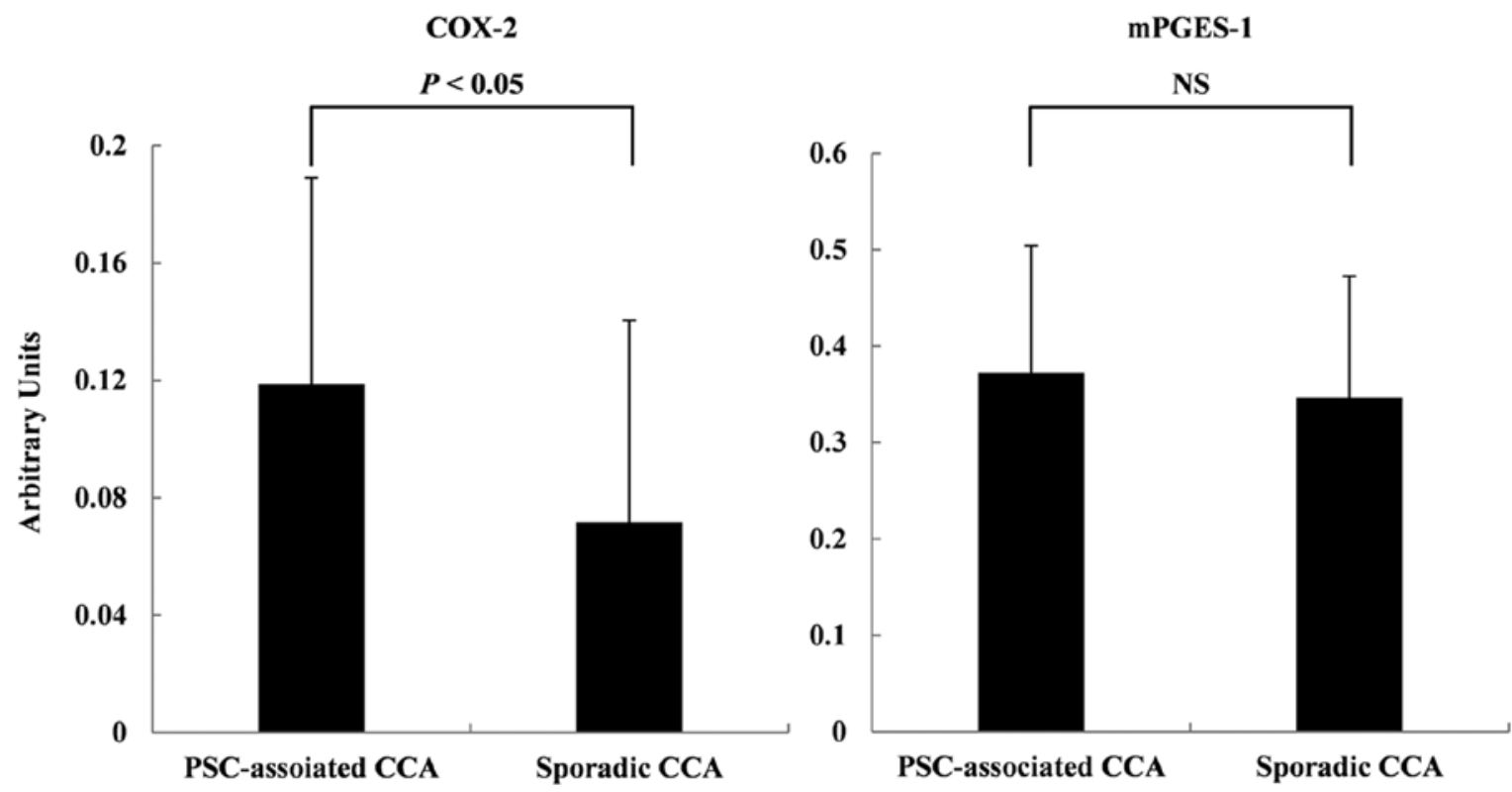

Figure 7. Real-time RT-PCR analysis of COX-2 and mPGES-1 mRNA expression in PSC-associated and sporadic CCA tissues. mRNA levels were normalized to those of glyceraldehyde 3-phosphate dehydrogenase, a housekeeping gene, and presented as arbitrary units. mRNA expression with the highest copy number for each gene was set to 1 . NS, not significant.

sion has been reported in non-neoplastic BDECs in PSC $(18,19)$. However, the correlation between COX-2 expression and carcinogenesis has not yet been investigated in patients. It is known that COX-2 is highly expressed in sporadic CCA (20-22), which might suggest its involvement in CCA progression via $\mathrm{PGE}_{2}$ production (23-25). Tsuneoka et al reported that a selective COX-2 inhibitor suppressed CCA development in hamsters (26), suggesting that COX-2 might be involved in cholangiocarcinogenesis. Our study demonstrated marked COX-2 expression in non-neoplastic BDECs and CCA tissues in PSC. This finding suggests that local $\mathrm{PGE}_{2}$ production might be elevated in both non-neoplastic BDECs and CCA tissues in PSC. $\mathrm{PGE}_{2}$ exhibits various effects, including cell proliferation, angiogenesis, and inhibition of apoptosis, and it plays an important role in cancer development and progression (12). Ki-67 immunohistochemical staining was performed to evaluate the cell proliferative effect of $\mathrm{PGE}_{2}$. Our findings demonstrated that cell proliferation was upregulated not only in CCA tissues but also in non-neoplastic BDECs in PSC. We suggest that in PSC, chronic inflammation could upregulate expression of COX-2 and mPGES-1, resulting in increased $\mathrm{PGE}_{2}$ production and promotion of carcinogenesis. Previous studies have suggested that nitric oxide-induced oxidative damage to DNA (27) and gene mutations due to activated cytidine deaminase (28) lead to PSC carcinogenesis. It is therefore believed that $\mathrm{PGE}_{2}$ acts as a promoter when BDECs in PSC that have acquired gene mutations form tumors and the cancer progresses.

This study investigated mPGES-1 expression in PSC. mPGES-1 is one of three types of PGES. Similar to COX-2, mPGES-1 is an inducible enzyme and its expression level is increased by inflammatory irritation (29). mPGES-1 expression is known to be elevated in various carcinomas (30-34), and mPGES-1 might be involved in the carcinogenesis of gastro- intestinal cancers that develop because of underlying chronic inflammation $(6,9,11)$. Lu et al (35) reported that mPGES-1 is overexpressed in human CCA tissues and that mPGES-1 promotes CCA development in SCID mice. Our study demonstrated for the first time that mPGES-1 is highly expressed not only in CCA tissues but also in the non-neoplastic BDECs in PSC. Cooperation of COX-2 and mPGES-1 might promote local $\mathrm{PGE}_{2}$ production.

Although weaker than in those of the PSC patients, COX-2 and mPGES-1 expression was observed in the non-neoplastic large BDECs of the control patients. This might be explained as follows. First, the non-neoplastic large BDECs used as controls were obtained from sporadic CCA patients. Many of these sporadic CCA patients exhibited cholangitis resulting from bile duct occlusion. Furthermore, all patients underwent cholangiography and treatment for obstructive jaundice prior to surgery. The irritation associated with temporary bile duct inflammation and preoperative treatment might have affected COX-2 and mPGES-1 expression. There were differences in the levels of COX-2 and mPGES- 1 expression in the non-neoplastic BDECs of the control patients. COX-2 and mPGES-1 expression is induced by inflammatory stimulation, but different transcriptional regulatory mechanisms are involved in the expression of each. While NF- $\mathrm{BB}, \mathrm{CRE}$, E-box, and NF-IL6 are believed to be important in the transcriptional regulation of COX-2 (36), Egr-1 plays a vital role in the transcriptional regulation of mPGES-1 (37). This difference might have had an effect on the transcriptional differences observed between the two enzymes.

In conclusion, COX-2 and mPGES-1 were highly expressed in PSC-associated CCA tissues and non-neoplastic BDECs in PSC and were involved in CCA development. However, the sample size of this study was small. It is therefore necessary to conduct a study using a larger sample size in order to clarify 
the correlations between COX-2/mPGES-1 and CCA carcinogenesis in PSC.

\section{Acknowledgements}

We are deeply grateful to Koji Arihiro and Cytotechnologist Miyo Oda of the Department of Anatomical Pathology, Hiroshima University Hospital for their kind support in performing Ki-67 immunostaining.

\section{References}

1. Rosen CB, Nagorney DM, Wiesner RH, Coffey RJ Jr and LaRusso NF: Cholangiocarcinoma complicating primary sclerosing cholangitis. Ann Surg 213: 21-25, 1991.

2. Bergquist A, Ekbom A, Olsson R, et al: Hepatic and extrahepatic malignancies in primary sclerosing cholangitis. $\mathrm{J}$ Hepatol 36: 321-327, 2002

3. Burak K, Angulo P, Pasha TM, Egan K, Petz J and Lindor KD: Incidence and risk factors for cholangiocarcinoma in primary sclerosing cholangitis. Am J Gastroenterol 99: 523-526, 2004.

4. Morris-Stiff G, Bhati C, Olliff S, et al: Cholangiocarcinoma complicating primary sclerosing cholangitis: a 24 -year experience. Dig Surg 25: 126-132, 2008.

5. Sheu BS, Yang HB, Sheu SM, Huang AH and Wu JJ: Higher gastric cyclooxygenase-2 expression and precancerous change in Helicobacter pylori-infected relatives of gastric cancer patients. Clin Cancer Res 9: 5245-5251, 2003.

6. Takasu S, Tsukamoto T, Cao XY, et al: Roles of cyclooxygenase-2 and microsomal prostaglandin $\mathrm{E}$ synthase-1 expression and beta-catenin activation in gastric carcinogenesis in $\mathrm{N}$-methyl$\mathrm{N}$-nitrosourea-treated K19-C2mE transgenic mice. Cancer Sci 99: 2356-2364, 2008

7. Giannitrapani L, Inqrao S, Soresi M, et al: Cycloxygenase-2 expression in chronic liver disease and hepatocellular carcinoma: an immunohistochemical study. Ann NY Acad Sci 1155: 293-299, 2009.

8. Takii Y, Abiru S, Fujioka H, et al: Expression of microsomal prostaglandin E synthase-1 in human hepatocellular carcinoma. Liver Int 17: 989-996, 2007.

9. Talero E, Sánchez-Fidalgo S, Villegas I, de la Lastra CA, Illanes $\mathrm{M}$ and Motilva V: Role of different inflammatory and tumor biomarkers in the development of ulcerative colitis-associated carcinogenesis. Inflamm Bowel Dis 17: 696-710, 2011.

10. Wilson KT, Fu S, Ramanujam KS and Meltzer SJ: Increased expression of inducible nitric oxide synthase and cyclooxygenase-2 in Barrett's esophagus and associated adenocarcinoma. Cancer Res 58: 2929-2934, 1998.

11. Jang TJ, Min SK, Bae JD, et al: Expression of cycloxygenase-2, microsomal prostaglandin E synthase 1, and EP receptors is increased in rat oesophageal squamous cell dysplasia and Barrett's metaplasia induced by duodenal contents reflux. Gut 53: 27-33, 2004.

12. Wang D and Dubois RN: Eicosanoids and cancer. Nat Rev Cancer 10: 181-193, 2010.

13. Koga H, Sakisaka S, Ohishi M, et al: Expression of cyclooxygenase-2 in human hepatocellular carcinoma: relevance to tumor dedifferentiation. Hepatology 29: 688-696, 1999.

14. Wendum D, Masliah J, Trugnan G and Fléjou JF: Cyclooxygenase- 2 and its role in colorectal cancer development. Virchows Arch 445: 327-333, 2004.

15. Jang TJ: Expression of proteins related to prostaglandin E2 biosynthesis is increased in human gastric and during gastric carcinogenesis. Virchows Arch 445: 564-571, 2004.

16. Davies G,Martin LA, Sacks N and Dowsett M:Cyclooxygenase-2 (COX-2), aromatase and breast cancer: a possible role for COX-2 inhibitors in breast cancer chemoprevention. Ann Oncol 13: 669-678, 2002.

17. Ermert L, Dierkes C and Ermert M: Immunohistochemical expression of cyclooxygenase isoenzymes and downstream enzymes in human lung tumors. Clin Cancer Res 9: 1604-1610, 2003.
18. Hayashi N, Yamamoto H, Hiraoka N, et al: Differential expression of cyclooxygenase-2 (COX-2) in human bile duct epithelial cells and bile duct neoplasm. Hepatology 34: 638-650, 2001.

19. Endo K, Yoon BI, Pairojkul C, Demetris AJ and Sirica AE: ERBB-2 overexpression and cyclooxygenase-2 up-regulation in human cholangiocarcinoma and risk conditions. Hepatology 36: 439-450, 2002.

20. Chariyalersak S, Sirikulchayanonta V, Mayer D, et al: Aberrant cyclooxygenase isozyme expression in human intrahepatic cholangiocarcinoma. Gut 48: 80-86, 2001.

21. Wu GS, Wang JH, Liu ZR and Zou SQ: Expression of cyclooxygenase- 1 and -2 in extra-hepatic cholangiocarcinoma. Hepatobiliary Pancreat Dis Int 1: 429-433, 2002.

22. Kim HJ, Lee KT, Kim EK, et al: Expression of cyclooxygenase-2 in cholangiocarcinoma: correlation with clinicopathological features and prognosis. J Gastroenterol Hepatol 19: 582-588, 2004.

23. Nzeako UC, Guicciardi ME, Yoon JH, Bronk SF and Gores GJ: COX-2 inhibits Fas-mediated apoptosis in cholangiocarcinoma cells. Hepatology 35: 552-559, 2002.

24. Wu T, Han C, Lunz JG 3rd, Michalopoulos G, Shelhamer JH and Demetris AJ: Involement of 85-kd cytosolic phospholipase A2 and cyclooxygenase- 2 in the proliferation of human cholangiocarcinoma cells. Hepatology 36: 363-373, 2002.

25. Han $\mathrm{C}$ and Wu T: Cyclooxygenase-2 derived prostaglandin E2 promotes human cholangiocarcinoma cell growth and invasion through EP1 receptor-mediated activation of the epidermal growth factor receptor and Akt. J Biol Chem 280: 24053-24063, 2005.

26. Tsuneoka N, Tajima Y, Kitazato A, et al: Chemopreventative effect of a cyclooxygenase-2-specific inhibitor (etodolac) on chemically induced biliary carcinogenesis in hamsters. Carcinogenesis 29: 830-833, 2008.

27. Jaiswal M, LaRusso NF, Shapiro RA, Billar TR and Gores GJ: Nitric oxide-mediated inhibition of DNA repair potentiates oxidative DNA damage in cholangiocytes. Gastroenterology 120: 190-199, 2001.

28. Komori J, Marusawa H, Machimoto T, et al: Activation-induced cytidine deaminase links bile duct inflammation to human cholangiocarcinoma. Hepatology 47: 888-896, 2008.

29. Jakobsson PJ, Thorén S, Morgenstern R and Samuelsson B: Identification of human E synthase: a microsomal, glutathione-dependent, inducible enzyme, constituting a potential novel drug target. Proc Natl Acad Sci USA 96: 7220-7225, 1999.

30. Yoshimitsu K, Altorki NK, Golojanin D, et al: Inducible prostaglandin $\mathrm{E}$ synthase is overexpressed in non-small cell lung cancer. Clin Cancer Res 7: 2669-2674, 2001.

31. Van Rees BP, Sivula A, Thorén S, et al: Expression of microsomal prostaglandin E synthase-1 in intestinal type gastric adenocarcinoma and in gastric cancer cell lines. Int J Cancer 107: 551-556, 2003.

32. Yoshimatsu K, Golijanin D, Paty PB, et al: Inducible prostaglandin E synthase is overexpressed in colorectal adenomas and cancer. Clin Cancer Res 7: 3971-3976, 2001.

33. Mehrotra S, Morimiya A, Agarwal B, Konger R and Badve S: Microsomal prostaglandin E2 synthase-1 in breast cancer: a potential target for therapy. J Pathol 208: 356-363, 2006.

34. Kawata R, Hyo S, Araki M and Takenaka H: Expression of cyclooxygenase- 2 and microsomal prostaglandin E synthase-1 in head and neck squamous cell carcinoma. Auris Nasus Larynx 37: 482-487, 2010.

35. Lu D, Han C and Wu T: Microsomal prostaglandin E synthase-1 inhibits PTEN and promotes experimental cholangiocarcinogenesis and tumor progression. Gastroenterology 140: 2084-2094, 2011.

36. Tanabe $\mathrm{T}$ and Tohnai $\mathrm{N}$ : Cyclooxygenase isozymes and their gene structures and expression. Rostaglandins Other Lipid Mediat 68-69: 95-114, 2002.

37. Subbaramaiah K, Yoshimatsu K, Scheri E, et al: Microsomal prostaglandin E synthase-1 is overexpressed in inflammatory bowel disease. Evidence for involvement of transcription factor Egr-1. J Biol Chem 279: 12647-12658, 2004. 